\title{
Differenz
}

Revista internacional de estudios heideggerianos y sus derivas contemporáneas

AÑO 3 NÚMERO 2: JULIO DE 2016. E-ISSN: 2386-4877 - DOI: 10.12795/Differenz.2016.i02.02

[pp. 29-46]

Recibido: $21 / 04 / 2016$

Aceptado: $14 / 06 / 2016$

\section{Heidegger: La paradójica existencia de la finitud del Dasein.}

\section{Heidegger: The paradoxical existence in finitude of Dasein.}

José Manuel Chillón Lorenzo

Universidad de Valladolid

\section{Resumen:}

La autenticidad de la existencia humana depende de una correcta correlación de los éxtasis temporales fundados en el futuro marcado por la muerte que el Dasein palpa desde la angustia. De esta manera, el vivir auténtico que se hace cargo de la temporalidad, ¿no supone ya una existencia neurótica? El artículo propone la necesidad de salvar este escollo desde la comprensión de lo que denominaré la trama psicológica de la existencia que, en el contexto de la Eigentlichkeit y de la Uneigentlichkeit, exige que la disposición afectiva de la angustia, se entienda completada por la de la serenidad. No se trata de salvar la finitud pero sí de una cierta redención en la finitud.

Palabras Clave: Existencia; futuro; neurosis; ansiedad; serenidad. 


\section{Abstract:}

The authenticity of human existence depends on a correct correlation of temporal ecstasy founded in the future marked by the death that Dasein palpated from anxiety. In this way, living authentic that takes care of temporality, is not a neurotic existence? This paper proposes the need to overcome this obstacle from understanding what I shall call the psychological plot of existence that in the context of Eigentlichkeit and Uneigentlichkeit requires that the emotional disposition of distress is understood supplemented by that of serenity. This is not to save the finitude but a kind of redemption in finitude.

Keywords: Existence; future; neurosis; anxiety; serenity.

\section{La vivencia existencial del tiempo en Ser y Tiempo.}

Existir no es un estar dado, sino que es un realizarse, un gestarse en el tiempo ${ }^{1}$.

Todo movimiento -en cuanto estar en camino hacia Badisis eis- consiste en un todavía-no-haber-alcanzado su hacia qué (su horizonte) (...) el andar considerado en su carácter ontológico es por principio distinto a lo ya andado ${ }^{2}$.

Para situarnos en nuestro tema, nos interesa sobremanera entender cómo la vivencia existencial del tiempo constituye la analítica existenciaria del Dasein cuyo hallazgo fundamental tiene que ver con la descripción de la cura como su esencia. La propia definición de die Sorge arroja luz sobre ello: preserse ya en el mundo como ser cabe los entes que hacen frente. El anticipar-se, el siempre-ya-ser y el estar-en medio, hacen que la cura esté vertebrada por el tiempo, constituida por una temporalidad entendida como gewesendgegenwärtigende Zukunft. Es este advenir (que en realidad es un movimiento mediante el cual el Dasein se hunde en su propia finitud ${ }^{3}$ ) para el que ha sido ciego la metafísica que no ha hecho la diferencia ontológica, el que es posibilitado por la temporalidad. En realidad, el Dasein ya está siempre en el mundo. A esta situación existencial es a la que Heidegger denomina facticidad como el nombre de nuestro existir propio ${ }^{4}$. Este encuentro con el

1. Vivir es estar en camino. La tarea de vivir es designada así por Heidegger transformando un concepto que Jaspers había forjado siguiendo a Kierkegaard. Cfr. Hans-Helmut GANDER, "La fenomenología hermenéutica del vivir fáctico de Heidegger", p. 164

2. HEIDEGGER, Interpretaciones fenomenológicas sobre Aristóteles, Madrid, Trotta, 2002, p.7

3. Así lo define PATOCKA, J.: Introducción a la fenomenología. Barcelona: Herder, 2008, p. 275

4. HEIDEGGER, M.: Ontologie Hermenéutik der Faktizität. GA 63. Vittorio Klostermann: Frankfurt a. M., 1988, p. 7. En Logik explica que, pese a que la existencia no es algo presente ni algo así como un hecho, sin embargo es un factum específico. $Y$ a este factum es el que denomina Faktizität. 
mundo, que es ahora comprendido como plexo de significatividades y siempre previo a todo proceso teórico-conceptual, ve a los entes del mundo como algo que está ahí (etwas Vorhandenes). Descubrir la aprioricidad, ya no formal more kantiano que redundaría en una subjetividad constituyente, sino material del existenciario ser en el mundo es la explicitación de que la manera prioritaria y primera que el Dasein tiene de ser en el mundo no es cognoscitiva ni teórica, sino hermenéutica. A esto nos referimos con que el Dasein se encuentra ante un mundo, su mundo, constituido por los significados, por las interpretaciones que ese mundo tiene para él y que son necesariamente heredadas, ya dadas y, por tanto, asumidas. Antes de tener que saber quién soy, ya sé que estoy en el mundo. Esta es la clave. El Dasein se descubre existiendo y teniendo que existir. Y esto es lo primero que sabe de sí mismo. El concepto de intencionalidad husserliano no ha sido capaz de reducir totalmente la asimetría entre sujeto y objeto. Por eso, al retrotraer Heidegger la subjetividad trascendental a la existencia fáctica se descubre esa unidad fundamental entre el Dasein y el mundo en términos de comprensión.

El tiempo empieza a formar parte de la esencia del ser del ente que es el Dasein y la consecuencia inmediata es el tener que albergar ontológicamente la finitud. Esta finitud es, a mi modo de ver, la consecuencia más decisiva que se deduce del existenciario fundamental del Dasein, in der Welt Sein, al permitirnos entender la existencia en términos agustinianos de caída (Verfallen) por ser el Dasein geworfener Entwurf. Cuando se sabe finito, cuando se descubre como no siendo una de las otras cosas del mundo, cuando vive existencialmente la diferencia ontológica y se comprende en previsión cierta a la muerte, entonces la existencia del Dasein, ya no del lado óntico sino desde la perspectiva ontológica, se hace auténtica al reconocerse en su pureza extática, proyectiva y por tanto nunca agotada en su aparecer presente, nunca deyectada al ínfimo nivel de las cosas que son en el sentido óntico (por ser disponibles Zuhanden o estar a la mano Vorhanden como las dos formas de ser de los entes intramundanos) y que tienen el modo de ser del estar presente ${ }^{5}$. El futuro se convierte no sólo en algo que todavía no está, sino más bien al contrario, en algo cuya realidad ya ha sido en el pasado y sigue siendo en un presente que nunca tiene sentido en sí mismo sino en el futuro que colma de plenitud ese ir siendo sido ${ }^{6}$.

Heidegger, M.: Logik. Die Frage nach der Warheit. GA 21, Vittorio Klostermann: Frankfurt a. M., 1976, p. 233.

5. Heidegger, M., Logik, p. 244.

6. Creo que la experiencia del cristianismo primitivo refleja mejor que ningún otro ejemplo la originalidad que supone la reordenación de los éxtasis temporales en Heidegger. La escatología paulina pone de manifiesto la especial vinculación del hombre creyente que no vive en el tiempo sino que vive el tiempo mismo. La esperanza cristiana está, por definición, desligada del tiempo en 
La lectura ontológica de las aportaciones de las filosofías de la vida otorgan una preeminencia especial a la existencia entendida ahora, lejos ya de los esquemas representativos tradicionales, como posibilidad de ser insistiendo así en lo abierto y dinámico de la vida. Por eso la vivencia del tiempo no puede cercenarse desde la comprensión de este como un mero transcurrir. Ser es existir que, a su vez, es haber de ser. Es central para la comprensión de la analítica existenciaria el hecho de que la comprensión que este ente que es el Dasein tiene ya del ser, esto es, la precomprensión que constitutivamente tiene del ser de los entes que posibilita la perentoria pregunta por el sentido del ser en general, no sea sino la tarea ontológica fundamental de este ente al que en su ser le va este ser ${ }^{7}$.

Ser en el mundo no solo arroja una determinada compresión del ser del ente que es el Dasein sino también un peculiar modo de ser del propio mundo ahora inabarcable e indisponible (no como los útiles que se dan dentro de él). Lo importante del mundo es la fenomenicidad de su ser fenómeno que ahora ya no se entiende como en Husserl desde el darse de lo eidético a la conciencia trascendental, sino como el abrirse (erschliessen) del mundo en cuanto totalidad de significaciones. En este mundo esencialmente abierto, el Dasein se encuentra. Puesto que, según hemos dicho, el mundo no se nos aparece como objeto en el sentido de objetividad sobre la que teorizar, la aparición del mundo al Dasein, la apertura del mundo, se hace en forma preteorética en determinados temples de ánimo que provocan en nosotros determinadas respuestas anímicas. Este estado de ánimo refleja cómo nos va. De hecho, lo expresamos así: cómo nos encontramos ante tal o cual acontecimiento. De modo que lo que nos afecta vivencialmente no es lo que sea entitativa o sustancialmente algo, sino cómo nuestra existencia resulta afectada por ello. Sin que quepa deducirse de aquí que el temple de ánimo sea ningún fenómeno subjetivo ni tampoco el efecto que algo tiene sobre el ser humano. Por el temple de ánimo, el Dasein se encuentra expuesto (Ausgesetztheit) en medio del ente en conjunto. Ente que no sólo se refiere a la naturaleza sino también a los otros, a los demás hombres ${ }^{8}$. El temple de

cuanto mensura de lo sucedido y se vincula, por el contrario, con el tiempo vivido, el tiempo de lo porvenir que es siempre el tiempo que no es presente, el tiempo de la inseguridad determinada por el advenir de un final, de la parousia, que ya ha venido en la encarnación del Verbo pero que siempre está llegando y que devasta las certezas de la inautenticidad de la vida mundana. Un tiempo no cronológico sino kairológico que, por tanto, se resiste a ser objetivado, cuantificado y que, para el que lo vive, se le presenta como el tiempo de la angustia.

7. Esta idea aparece ya había aparecido casi exactamente formulada en las lecciones de 19251926, Logik. La existencia, explica Heidegger, tiene la forma fundamental de ser de que en su ser le importa su propio ser. Cfr. HEIDEGGER, Logik, p. 225.

8. Ya que la existencia solo es "como es en el ser con los demás". HEIDEGGER, M.: Hölderlins Hymnen "Germanien" und "Der Rhein". GA 39, Vittorio Klostermann: Frankfurt am Main, 1980, p. 143. 
ánimo abre el ámbito en el que Dasein y mundo se encuentran constituyendo así la propia manera de ser del encuentro en cuanto situación en la que el Dasein, los otros, y los entes intramundanos se hayan implicados ${ }^{9}$. Este estar afectado consustancial a nuestro estar ya en el mundo es lo que Heidegger expresa con el giro geworfener Entwurf. Echados pues a vivir tenemos que hacerlo ya que en ello se resume lo que somos. A esto se refiere con el concepto de facticidad. Pero es que, además, este ser en del ser en el mundo nos sumerge en la estructura de la comprensión que es la estructura de nuestra propia existencia. Y así como existir es tener que hacerlo, la comprensión lejos de ser una tarea preeminentemente epistémica es una determinación existencial que marca lo que puede hacerse teniendo en cuenta que este poder hacerse está en obligatoria coherencia con el poder ser del Dasein como ek-sistencia, como ente cuyas posibilidades de ser definen su ser proyectivo, futurizo, abierto que, al comprender sus posibilidades se comprende a sí mismo. El Dasein, como ser de posibilidades en un mundo abierto al que se refieren esas posibilidades, descubre el mundo como un conjunto de significatividades al abrise a la palabra, al habla que no puede confundirse con el lenguaje, al ser aquella el fundamento ontológico-existencial de este.

Todo esto es lo que está incluido en la concepción de la esencia del Dasein como cura. Lo decisivo para la problemática filosófica, y esto desde las obras de juventud, es el análisis del existir. Pues bien, este encontrarse fáctico devuelve al ser humano una forma de ser esencial definida en términos de cuidado. El cuidado es el fenómeno fundamental del existir ${ }^{10}$. Heidegger hacía poco había definido como movilidad del trato a lo propio del vivir en cuanto vivir en el mundo y es a esa movilidad a la que llamó Sorge como un intenso andar en busca de algo, estar ocupado en algo (Aussein auf etwas). Este cuidado que sustituye a la intencionalidad como relación fundamentalmente teórica con el mundo y que es reconducida al cómo del comportarse respecto a algo, ve al mundo desde las direcciones del cuidado que Heidegger entiende como mundos del cuidado y que distingue en mundo circundante, mundo compartido, mundo del sí mismo. Al entender el cuidado existencialmente como la esencia del ser del Dasein, lo hemos mencionado ya, se explica por qué la existencia del ser en el mundo no significa existir como las otras cosas que subsisten sino que el ek-sistir en cuanto cuidarse pueda tener que ver con: "atender, fabricar, atender los negocios, tomar posesión de algo, impedir, preservar de daños o pérdida"11.

9. "Existir como Dasein significa mantener abierto un ámbito que consiste en poder percibir las significaciones de las cosas que le son dadas y que lo interpelan a partir del despojamiento de éste". HEIDEGGER, M.: Seminarios de Zollikon. Barcelona: Herder, 2006, p. 30. En adelante ZS.

10. HEIDEGGER, Ontologie, p.104

11. Ib. p. 102 
Esta inclinación de la existencia al mundo, esta tendencia intrínseca del existir humano a las cosas es lo que se entiende con la noción de cuidado.

Al ser existencia ek-sistente, abierta y proyectiva, su vivir consiste en anticiparse al elegir sus posibilidades en un mundo de cosas en el que se descubre yecto, arrojado. Esta es la peculiar situación paradójica de la existencia humana que es cabe los entes intramundanos entre los que puede perderse cómoda y anónimamente dando así holgura a esa inapelable situación de caída que siempre trata de reducir su haber de ser a una mera existencia perdida entre las cosas a partir de las cuales entiende e interpreta su propia existencia. Pero lejos de estar a gusto entre las cosas, la existencia del Dasein si quiere autentificarse tiene que descubrir la inhospitalidad (Unheimlichkeit) del mundo para con él. Ese no ser de este mundo del Dasein genera en él el temple de ánimo, la disposición afectiva (Befindlichkeit) fundamental y coherente con su apertura y su ser de posibilidades: la angustia. Y la angustia, a la vez que cuestiona nuestra ciudadanía entre las cosas, nos permite vislumbrar que no somos sino en camino hacia la muerte donde toda posibilidad queda tan plenificada y realizada como resuelta y anulada. De ahí que sea la angustia la marca indeleble de la paradójica situación existencial del Dasein. La angustia es la expresión fundamental de la apertura del Dasein que vislumbra, se adviene y es consciente del fin inapelable. Este fin no es solo final (futuro) sino principio (pasado) y realidad (presente) ${ }^{12}$. Estando ya como posibilidad no solo barruntada y más o menos probable sino como posibilidad última y definitiva, planea sobre el pasado de caída y sobre el presente de facticidad colmando la existencia de finitud. Todo esto es la finitud: asumir lo que ya se ha sido desde lo que inapelablemente ha de ser. De ahí que la finitud afecte a toda la temporalidad, como no podía ser de otra manera siendo esta el sentido del ser del ente que es el Dasein. Y esta finitud del Dasein es la que reclama que, al no poder ser él el fundamento de sí mismo, se constituya como ente en cuanto dependiente del ser.

La finitud está así pues indeleblemente unida a la existencia lo que le devuelve una negatividad que Heidegger entiende en términos de culpabilidad y que, por supuesto,

12. En la esencia del Dasein está ya incluido el entre (Zwischen) que se relaciona con el nacimiento y la muerte en el que el nacimiento no es algo pasado que ya no está ni la muerte algo futuro que todavía no ha llegado, sino que el Dasein es el entre en relación a la unidad que se da entre la condición de arrojado (pasado) y el estar vuelto hacia la muerte (futuro) inherente al cuidado. No puede pues quedar fuera de consideración el estar vuelto hacia el comienzo (Sein zum Anfang) y el extenderse (Erstreckung) entre el nacimiento y la muerte y pasar por alto lo que Dilthey llama "la trama de la vida" (Zusamenhang des Lebens) que no es una mera secuencia de vivencias que tienen que ver con la concepción vulgar del tiempo. Cfr. el trabajo de WALTON, R.: "Temporeidad e historicidad" en RODRíGUEZ, R.: Ser y Tiempo de Heidegger. Un comentario fenomenológico. Madrid: Tecnos, 2015, pp. 371-397. 
nunca debe asimilarse a ningún error o conducta que haya de ser corregida. Cuando la existencia se gesta o sucede de tal modo que asume la posibilidad de la muerte, cuando se toma la decisión de vivir la propia finitud entonces el Dasein se hace responsable de esa culpabilidad. Así, la existencia encuentra su gestarse original al que Heidegger llama destino (Schicksal) y que no puede separarse de lo que también Geschick o destino colectivo $^{13}$. La existencia auténtica, siguiendo Ser y Tiempo, consiste en no diluirse la existencia en los entes que nos hacen frente y de los que nos cuidamos, sino en pensar la existencia en cuanto vuelta hacia la muerte como futuro propio que se retrotrae al haber sido originario marcado por la condición de arrojado. Nosotros, explicará Heidegger en Ontologie, estamos en medio de esa caída que ha constituido toda la historia fraguada como encubrimiento de lo originario. Asumir esta temporalidad pone al Dasein en el estado de resuelto, esto es, la prolongada constancia (erstreckte Ständigkeit) de la existencia en su mismidad. No se trata pues de un suceso que pasa en el efímero presente sino de un acontecer (Geschehen) que implica tanto movilidad (y no movimiento como sería propio de los entes que no tienen la peculiaridad del Dasein) como persistencia (que no es tampoco perdurar, Beständigkeit) y que debe ser entendida como estabilidad del sí mismo (Selbständigkeit).

\section{Tiempo y apertura: la finitud}

El proyecto determinante -advierte Heidegger- del ser humano como Dasein en el sentido extático es un proyecto ontológico, mediante el cual se supera la representación del ser humano como subjetividad de la conciencia. Este proyecto, lo acabamos de ver, viene determinado por la comprensión del ser en tanto constitución fundamental del Dasein ${ }^{14}$.

El carácter de abierto para lo presente es el rasgo fundamental del ser humano. Pero el carácter de abierto para el ente cobija en sí diversas posibilidades. Lo que rige todo carácter de abierto es el inmediato estar en medio de las cosas que nos incumben en persona ${ }^{15}$.

13. La puesta en circulación de sus Schwarze Hefte llevará a la lectura de este destino colectivo como aquella dimensión futura que el pueblo alemán tiene que alcanzar y que parece poder consagrarse con el nacionalsocialismo de Hiltler. No importa la política, ni la concreción de los hechos históricos o las personas responsables sino el metafísico deber ser del pueblo que cumple así su destino. Para nuestro tema, sería destacable hasta qué punto el acento en exceso del futuro de lo porvenir, a pesar de que se haya hecho patente en lo ya sido, obvia la responsabilidad para con el presente concreto donde reside el sufrimiento y el dolor singular que no puede ser subordinado a ningún destino colectivo supremo.

14. Cfr. ZS, p. 187-188.

15. ZS, p. 127. 
Como es bien sabido, Heidegger nunca aceptó las interpretaciones existencialistas ${ }^{16}$ de su trabajo al no haber entendido que la analítica existenciaria no tenía sentido en sí misma sino como ontología fundamental propedéutica de una investigación sobre lo que ha ocupado a la filosofía desde sus albores: la cuestión del ser. De hecho, según advierte Heidegger a quienes han pretendido interpretar la analítica existenciaria del Dasein en los términos del análisis, al pasar por alto esta referencia al ser como ser del ente, ni siquiera hacen un análisis del Dasein. En relación al tema que nos ocupa, "el análisis psiquiátrico del Dasein supone la interpretación insuficiente del ser-en-el-mundo (...) al trabajar con un Dasein recortado"17. Ahora bien, de lo que Heidegger no podía apearse era de la imagen de hombre que resultaba de entender la existencia humana en esa relación constituida en dependencia con el ser. Efectivamente, el Dasein es un ente tan entre los entes como distinto de ellos. Su particular ser se caracteriza por esa naturaleza paradójica que le hace descubrirse caído entre los entes a la vez que radicalmente distinto de los demás entes por ser un ente al que le determina existencialmente preguntarse por el ser. Por ser cabe los entes, nunca puede rebasar el nivel de la mundaneidad en la que está. Por irle el ser, ya siempre está en el contexto de la pregunta, ya siempre tiene una precomprensión ontológica del sentido del ser en general, ya siempre se sabe como no agotado en el aparecer sino proyectado hacia sus posibilidades. Esta doble faz ontológica es la que resume el ser del Dasein como proyecto yecto.

Lo que vamos a analizar aquí es, cómo esa definición en términos de apertura que conmina al Dasein a no poder ser encapsulado en el concepto de objeto (Gegenstand) y a constituir su existencia como mera posibilidad, le viene determinada por la vivencia del tiempo. ¿Cuál es la contrapartida psicológica de esta manera de vivir el tiempo en la que el futuro es el éxtasis matriz? O como lo menciona Heidegger siguiendo la estela de Ser y Tiempo: ¿Cómo se relaciona el ser humano mismo con el tiempo? ¿Cómo resulta determinado el ser humano por el tiempo de modo que el Dasein pueda ser interpelado

16. Heidegger se refiere a ella como la ridiculez de la filosofía de la existencia que en nada es mejor que la filosofía de la vida. Cfr. HEIDEGGER, M.: Schwarze Hefte: Überlegungen II-VI (1931-1938). Frankfurt a. M: Vittorio Klostermann, 2014, p 19.

17. Cfr. ZS, p. 278. "La pregunta surgida necesariamente de esta forma, ¿quién o qué o cómo es el ser humano? Es tratada en Ser y Tiempo exclusiva y constantemente con respecto a la pregunta por el sentido del ser. Con esto, ya está decidido que la pregunta por el ser humano en Ser y Tiempo no es planteada en forma de una antropología filosófica que pregunta qué es el ser humano en sí y para si". ZS, p. 193. A pesar de ello, Heidegger criticó años después que Ser y Tiempo todavía se mantiene en la orientación metafísico-antropológica al privilegiar, en la exposición de la autenticidad de la existencia, demasiado el plano existencial. Cfr. HEIDEGGER, M. Schwarze Hefte, p. 347: La filosofía existencial es aun antropología y metafísica porque ella no pregunta la pregunta fundamental de la verdad del ser. 
por el ser ${ }^{18}$ La tesis central de Heidegger es que la mayoría de las enfermedades psíquicas tienen que ver con una perturbación del existir al no lograr sostenerse hacia fuera. Para que pueda entenderse la repercusión psicológica de esta analítica existencial hay que aceptar las consecuencias que para las ciencias humanas tiene esa comprensión del hombre como ek-sistente y abandonar, a la vez, el patrón de cientificidad que parece instalarse "dogmática y unilateralmente a partir del carácter científico de la física moderna"19. Sin duda, pues, lo más importante es lo que significa el abandono de la noción del Dasein como sujeto, como conciencia en tanto subjetividad que se enfrenta a un objeto ${ }^{20}$. Como el Dasein no puede ser objetivado (tal como pretenden la antropología o la psicopatología omitiendo con ello la pregunta de qué es el ser humano ${ }^{21}$ ) la psicología consecuente deberá dejar de pensar en el alma humana como caja de resonancia de los sucesos exteriores al hombre desde ese dualismo previamente asumido del alma y cuerpo, exterior e interior, exógeno y endógeno, aunque luego resulte mitigado por el descubrimiento de las múltiples vinculaciones psicosomáticas ${ }^{22}$. Es más, una concepción de la psiquiatría y de la psicología desde el paradigma del naturalismo de la física, no puede dar ni explicación científica ni tratamiento terapéutico, por ejemplo, a la enfermedad típicamente contemporánea como es -en palabras de Medard Boss ${ }^{23}$ - el aburrimiento y la falta de sentido que ya no muestran una sintomatología patológica específica y determinada en el sentido de perturbaciones localizadas de tipo físico o psíquico. En este sentido, la situación reemplaza a la reacción. La situación supone un corte transversal en la relación originaria con el mundo como seren-el-mundo. De esta manera, la psiquiatría debe tener en cuenta que lo que hace frente en una situación (sea un estímulo, un trauma etc...) no se presenta en forma acabada

\section{ZS, p. 192}

19. ZS, p. 215. "Si observamos también que la ciencia como tal es un actuar y una obra del ser humano, entonces se muestra un extraño entrecruzamiento de la pregunta por una ciencia del ser humano con la pregunta, cuyo ser humano hace posible por vez primera la ciencia". p. 216.

20. "La objetualidad que en el pensamiento moderno significa lo mismo que objetividad supone una modificación de la presencia de las cosas. La presencia es entendida ahí por su representacionalidad mediante un sujeto (...) La presencia ya no es tomada como lo dado a partir de sí, sino tal como se contrapone a mí en cuanto sujeto pensante, como es ob-jetado hacia dentro de mi". ZS, p. 163

21. ZS, p. 235.

22. Es de destacar la referencia amplia que hace Heidegger a una conferencia de R. Hegglin: "Was erwartet der Internist von der Psychosomatik?". En ella el Dr. Hegglin resume con el concepto de psicosomática todas las influencias mutuas entre psique y soma y que van más allá de las enfermedades emocionales. Cfr. ZS, p.144. Más adelante, atendiendo al peculiar fenómeno del estrés, explicará Heidegger, lo importante que es entenderlo desde el punto de vista del ser humano existente sin operar por ello una reducción físico-fisiológica a estímulos sensoriales.

23. ZS, p. 243 
sino como tarea a realizar. Cuando esa situación resulta asumida, entonces, ella misma se convierte en medio para poder superarla ${ }^{24}$.

Pensar el ser, lejos de ser algo arbitrario y místico ${ }^{25}$, permite a las ciencias, y en especial a la psicología, pensar la repercusión vivencial de la diferencia ontológica obviada por el trato exclusivo con el ente cuyo resultado pretende ser la verdad objetiva. Se constata, "el abismo que hay entre la ciencia natural y la consideración del ser humano"26. Y entonces, ahora sí, la psicología deberá hacerse cargo de la transformación de la existencia resultante de la percepción de la diferencia ontológica. Se trata de sacar las consecuencias que tanto para el estatus de cientificidad de la psiquiatría y de la psicología, como para el objeto de las mismas, esto es, el ser humano, tiene la diferencia ontológica cuya explicitación había sido la tarea filosófica por excelencia. Y en nuestro caso, nos interesa en qué medida el hacer patente la diferencia ontológica implica hacerse cargo de una comprensión distinta del tiempo.

Desde Aristóteles a Husserl pasando por San Agustín o Bergson entre otros, ya se sabe que el tiempo tiene que ver con el alma ${ }^{27}$, que la medida del tiempo de la conciencia es duración, que el tiempo de la conciencia trascendental se refiere al transcurrir cuyos ahoras resultan enriquecidos por la síntesis producida por la retención del pasado y por la protección del futuro por referirnos a las Lecciones sobre fenomenología de la conciencia interna del tiempo de Husserl. Sin embargo, todas estas aportaciones, aun habiendo atisbado algunos de los problemas capitales del concepto de tiempo, pertenecen a la concepción tradicional del mismo (la comprensión vulgar del tiempo o tiempo del ahora ${ }^{28}$ ) apoyada en tres pilares: a) el tiempo se muestra como la sucesión de ahoras puntuales; b) el tiempo no es sin psique, sin animus, sin conciencia; c) el tiempo es determinado respecto a su ser a partir de la comprensión del ser en el sentido de presencia (Präsenz $)^{29}$.

24. DöRR, O.: Psiquiatría antropológica. Contribuciones a una psiquiatría de orientación fenomenológico-antropológica. Santiago: Universitarias, 1995, pp. 51-52.

25. ZS, p. 46

26. ZS, p. 57. Y así, el problema es que se pretende ver al ser humano desde la consideración de un método que no ha tenido en cuenta la esencia particular del Dasein. "Evidentemente se puede considerar al ser humano también de modo científico-natural como una parte de la naturaleza. Sólo que permanece la pregunta de si con eso resulta algo humano que dé con el hombre en cuanto hombre". p. 59

27. ARIStóteles, Física, 223a, 21ss. "En ti, mi alma, mido yo los tiempos". S. Agustín, Confesiones, XI, 27. Puede verse un interesante repaso a esta concepciones en el § 19 de Logik, pp. 244-273

28. HEIDEGGER, M., Logik, p. 246. Se trata de una comprensión del tiempo que deje de lado la diferenciación entre tiempo objetivo y tiempo subjetivo, entre tiempo inmanente y tiempo trascendente.

29. ZS, p. 107 
El tiempo, pues, concierne especialmente al hombre ${ }^{30}$. Tan importante es contextualizar la cuestión del tiempo en lo referente a la diferencia ontológica que, de no hacerlo, esto es, de considerar el tiempo como una mera sucesión de ahoras vacíos, la psicología perdería de vista la relación original y esencialmente constitutiva del Dasein con el tiempo que se encuentra perturbada en los pacientes psíquicamente enfermos. No es que estos no perciban el encadenamiento natural de unos ahoras con otros siempre susceptible de ser calculado y captado por los métodos científicos tradicionales, sino que queda oculto para ellos la interpretabilidad (Deutsamkeit) del tiempo ${ }^{31}$, lo que comúnmente designamos con el tener tiempo para algo. Heidegger ya sabe que algunas investigaciones de médicos psiquiatras van en esta dirección. Es el caso del trabajo de Franz Fischer sobre la perturbación de la estructura espacio-temporal en los pacientes esquizofrénicos. Puesto que lo que rige en el estar abierto es precisamente el inmediato estar en medio de las cosas que nos incumben, lo que se constata en la esquizofrenia es la privación de este carácter de abierto que no desaparece pero que resulta empobrecido. Así las cosas, la aportación heideggeriana consiste precisamente en dar la vuelta a aquella concepción tradicional del tiempo para asegurar que, en primer lugar y más fundamental, la forma de ser del tiempo debe ser determinada respecto de la comprensión del ser ya no en términos de presencia sino con el privilegio de la dimensión futura que determina al Dasein por sus posibilidades proyectivas. No resulta difícil entender que, entonces, lo que importa del tiempo no es el sucederse de los ahoras sino el transcurrir de quien no vive en el tiempo sino que vive el tiempo hasta llegar a alterar la dirección de dependencia entre la conciencia y el tiempo. De esta concepción heideggeriana se despliegan tres caracteres fundamentales del tiempo: su interpretabilidad, el carácter del entonces, esto es, del estar-fechado, la amplitud temporal de un ahora que está siendo y que no se agota en el puro presente instantáneo, y por último, la publicidad del ahora, esto es, "el ahora en cada caso dicho es el ahora que nosotros decimos"32. De hecho, lo que Heidegger reprocha al psicoanálisis freudiano es que a costa de centrarse en la prehistoria del sufrimiento, dificulta así la relación con el presente marcada por esa relación abierta con el mundo constituyendo así el espacio intermedio en el que se muestran los hombres y las cosas.

30. ZS, p. 75.

31. Cfr. ZS, p. 82. Es nuestro estar en el tiempo, el que funda el tener tiempo. Se hace cargo Heidegger de la tesis de Einstein por la cual su Teoría de la Relatividad habría quebrado la concepción tradicional del tiempo de la física. Esta opinión cada vez más extendida -cree Heidegger- es un error. De lo que aquí está hablando Einstein es de la medición del tiempo no de lo que el tiempo es. Y por tanto su propuesta es una alternativa a la medición del tiempo absoluta para reconocer que ella es necesariamente una medición relativa y condicionada. Cfr. ZS, p. 104.

32. ZS, p. 90 
Es muy interesante ver cuál fue su lectura de Ser y Tiempo durante los encuentros en Zollikon. Una lectura que advierte que lo esencial de su aportación consiste en entender que lo que distingue el ente que es el Dasein de otros entes intramundanos es el $D a$ que nombra la apertura "en la que un ente puede estar presente para el ser humano, inclusive él mismo para sí mismo"33. Este Da siendo lo abierto determina una espacialidad que pertenece al claro en el que el Dasein está en relación al ser y en el cual se halla como existente. El poder-ser del Dasein es análogo, según explica Heidegger, a las posibilidades que de suyo tiene la realidad, en términos aristotélicos, a la potencialidad que forma parte de su ser propio. Por eso las posibilidades que constituyen esencialmente al Dasein y determinan su libertad no son añadidos que pudieran no realizarse por ser meras opciones o permanecer simplemente como puras posibilidades, sino intrínsecamente constitutivas de su ser esencialmente proyectivo. La interpretación posterior de la relación Ser y Dasein y de la apertura de este en términos de Lichtung lo entiende Boss como el encontrarnos enfrentados a diversas posibilidades de relacionarnos con las cosas.

El existir auténtico tiene que ver con el hacer propias algunas de esas posibilidades, tiene que ver con poder elegir libremente qué posibilidades son las propias ${ }^{34}$. La existencia humana la ve Boss en una relación de cuidado respecto a dicha apertura y la tarea del médico como la de un cuidado que se adelanta y libera al otro para enfocarlo a sus posibilidades propias. Nuestro ser en el mundo tiene la característica de que nos permite ser capaces de dejarnos decir algo por las cosas sin que esto sea algo puramente pasivo sino un co-responder mutuo. No estamos encerrados en nuestra psyche para luego salir al mundo exterior sino que ya estamos en la apertura con las cosas. Estar ya afuera es algo peculiar de la existencia humana. El mundo en el que el Dasein ya está es tanto más reducido cuanto más patológica sea la personalidad del ser humano ${ }^{35}$.En este sentido, las enfermedades psicóticas pueden ser diagnosticadas como desórdenes en la dimensión de la apertura: apertura intensa por momentos y de cerrazón absoluta en otros.

Heidegger mismo resuelve una cuestión que ronda siempre la interpretación de la

\section{ZS, p. 193}

34. Sacar las consecuencias que para una posible psiquiatría fenomenológica tendría la consideración del Dasein como ser-en-el-mundo supone una posible reinterpretación de las enfermedades mentales desde la aceptación de que el verdadero modo de conocer una enfermedad exige la descripción del mundo que le constituye. En esto consiste el análisis existencial de Binswanger al descubrir un nivel de experiencia y de interpretación más profundo. Esto es lo que explica Blankenburg, W.: "Daseinsanalyse". In: J. RitTeR (ed.). Historisches Wörterbuch der Philosophie II. Darmstadt, 1972, p. 22.

35. Binswanger habla así del mundo etéreo del maníaco cuya temporalidad es la del salto o el mundo retorcido y empobrecido del esquizofrénico. 
obra más importante de su pensamiento: ¿por qué habla de Dasein y no sencillamente de ser humano? Dejamos que él mismo responda tal y como lo hizo el 23 de noviembre de 1965: "La razón de esto es que en Ser y Tiempo la pregunta por el ser determina todo, es decir, la pregunta sobre en qué medida ser (presencia) tiene su patencia en el tiempo" ${ }^{36}$.

Es la mejor manera de expresar que el ser humano, lejos de las formulaciones clásicas que ponen el acento en la racionalidad o en la subjetividad, es precisamente tal al comprender, y esta ontologización de la comprensión determina que tal comprensión no sólo no sea una actividad del Dasein sino su forma típica de ser en el mundo. Una comprensión que no sólo no es ajena a su ser o exterior al Dasein sino que es la que corresponde a su situación vital, concreta y fáctica, lo que ya Heidegger denomina la situación hermenéutica fundante previa a toda construcción teorizante sólo posible por el estar del Dasein en la apertura del ser. No hay un antes y un después en el saber de sí del Dasein, sino que a la vez que está siendo en el mundo, proyectando sus posibilidades coherentes con la aperturidad de este mundo, se encuentra en la iluminación del ser (Lichtung) a cuya luz se le aparecen los entes. Esta dependencia del Dasein con respecto al ser, entendida de distintas maneras en las distintas fases del pensamiento heideggeriano, es la que deja al descubierto su concepción del tiempo.

\section{La autenticidad vivida: angustia y serenidad desde la libertad}

Pero, ¿esta concepción futuriza del tiempo no embarga al ser humano en un vuelco constante hacia lo por-venir que, por mucho que ese futuro sea ya sido, convierte el tener que vivir en una especie de superación del presente? Y entonces, ¿la angustia resultante de esta forma de vivir, a pesar de ser la mejor muestra de la apertura del Dasein, y aunque tenga una contrapartida ontológica evidente, no devuelve al hombre a una situación existencial y psíquicamente imposibilitante del mismo hecho de vivir? ¿Y el peligro de perderse en esa tergiversación ontológica (que se produce cuando el ser humano se refugia en las oportunidades de subsistencia) no será más que un peligro una salvación de esa angustia insoportable resultante de una existencia en adviento perpetuo? La vida se convierte en una carga que devuelve al hombre el estrés necesario y consecuente con su ser ek-sistente y que, según Heidegger, debe ser leído en relación al fenómeno de la caída. El estrés, en cuanto posibilidad originaria de un existir que es estar siempre y antes que nada relacionados con algo, debe ser explicado en términos de solicitud (ante lo que nos interpela como seres de posibilidades) y de correspondencia. Y estas dos dimensiones se advierten desde la otra dimensión del diálogo en sentido amplio que incluye "un hablar

36. ZS, p. 194 
con las $\operatorname{cosas}^{\prime \prime 37}$ que hace posible la interpretación o la forma básica y fundamental del estar finito del Dasein en el mundo, lo que en sus primeras obras denominó hermenéutica de la facticidad. Existir es, pues, "soportar (aus-stehen) un ámbito de apertura"38.

El pasado de caída es el ya sido del haber de ser de la muerte: la finitud. La más inminente repercusión psíquica de esta vivencia existencial del futuro sombrío de la muerte es la ansiedad. Es más, una existencia en la que el pasado es caída y el futuro muerte, no tiene muchas salidas redentoras en el presente. Cualquier forma de vivir lleva consigo la espada de Damocles de la muerte coartadora. Cualquier obra humana prevé ya su inevitable descomposición futura. Cualquier triunfo humano proyecta un insoportable eco en forma de memento mori. En nada puede el ser humano descansar, con nada puede el ser humano conformarse, por nada puede el ser humano motivarse para vivir... El Dasein, más que portar la vida y la existencia, la so-porta, la aguanta. Abismo es la existencia y abismo es el final. La nada envuelve, cobija y explica nuestro ser. Y por eso esta manera singular de percibir la nada sólo puede hacerse, no mediante teorías ni filosofías, sino mediante una forma de encontrarse que es la angustia. Por medio de ella el ser humano se sabe habitando en el ser del que, lo único que puede saberse es que no es como los entes y en este sentido no es nada. La autenticidad de la existencia en Heidegger precisa de una constante despedida del ente que se consagra definitivamente en la muerte.

Pero Heidegger parece adelantarse a este sinsentido existencial. La finitud del Dasein es la más conspicua explicación de que el Dasein no puede explicarse por sí mismo, de que no se agota en sí. Al no agotarse en su mismidad, entiende su esencia como apertura y esta como existencia inagotable en términos de referencia dependiente al ser. Existir no tiene que ver con la penumbra que se adivina en la interpretación existencialista y nihilista que se agota en lo óntico, sino con la claridad del ente que es estando en el claro del ser desde el que se abre como posibilidad de ser y desde el que descubre la apertura del mundo. Frente a la cerrazón del Dasein $^{39}$ que se encuentra caído y quiere seguir estándolo al fijar su atención en las cosas y quedarse perdido en ellas en un desmoronamiento ontológico sin par, la Offenheit, debido a su ser dependiente del ser, le saca de las garras del estar encerrado en $\mathrm{si}^{40}$, del egoísmo óntico hacia una especie de donación ontológica.

\section{ZS, p. 221}

38. Ib. p. 318

39. "Se establecen así las bases para una práctica terapéutica referida, no ya a un sujeto enfermo, sino a una forma de ser que es apertura en el mundo y que puede dañarse a sí mismo por una "cerradura" severa en torno a su propia apertura en sus comportamientos con los otros y con las cosas". XolocotZI YÁÑEZ, A.: "Los encuentros de Heidegger con la psiquiatría: Badenweiler y Zollikon", en La Lámpara de Diógenes, no 16 y 17, pp. 7-23.De la cita, p. 18.

40. Este estado de cerrado es, según menciona Dörr, una descripción muy profunda de lo que ocurre 
Y sobre todo que, hacer del ser humano un ser de posibilidades es hacerle dueño de su libertad. No tanto porque tenga libertad sino porque la libertad le tiene a él en cuanto espacio determinado por la claridad proyectada por el ser en la existencia humana. Por eso, entran en la trama existencial del Dasein, tanto la apertura a lo que nos supera y nos funda como la clausura en el mundo para confundirse con uno más de los seres del mundo. En este sentido puede decirse que no pueden separarse las nociones de facticidad, caída y proyecto existencial ${ }^{41}$.

Desde la comprensión global del trabajo de Heidegger, creemos que es interesante insistir en la complementariedad entre la angustia ante el inevitable futuro ya venido y la serenidad ante el presente en el que la existencia tiene que vivir. El ser sí mismo que marca la autenticidad de la existencia se constituye en la medida en que la caída originaria no tiene la última palabra ${ }^{42}$. El pasado es indeleble no porque haya sido sino porque es el haber sido de un haber de ser como posibilidad cierta e inapelable. Si la caída fuera toda la existencia del Dasein, quedaría evaporada la diferencia ontológica que permite a la existencia ser siendo, abrirse y proyectarse. La tentación de huir de sí para encerrarse en las cosas o en sí mismo, en cualquier forma de materialismo o de egoísmo, es la reacción posible ante la dificultad de vivir en el estado de angustia. La angustia es precisamente la fuga que no tiene un objeto concreto del que huir, que no tiene un "ante qué" que sea un ente intramundano sino que la angustia es ante el "ser en el mundo" en cuanto tal ${ }^{43}$. Por eso la angustia no es un temor determinado que fija el objeto de su miedo en algo que es "a la mano" o "ante los ojos". Al no fijarse en nada del ente, es el mundo el que adquiere una total insignificatividad y en ese sentido, abre el mundo como mundo. La angustia recuerda al Dasein su estado de caído y arrojado y, al ponerle delante de sí su ser en el mundo, le enfrenta a su ser más puro, a su ser abierto, a su ser proyectivo. Por eso la angustia saca al Dasein de su tendencia permanente a superar esa inhospitalidad en la que se encuentra al saberse yecto entre las cosas del mundo. La angustia rescata al Dasein

con el estado depresivo: él es empujado hacia su facticidad hacia su condición de mera naturaleza determinada. Cfr. DöRR, p. 231.

41. CAPURRO, R.: "Análisis existencial y relación terapéutica: la influencia de Martin Heidegger en la obra de L. Binswanger y M. Boss" en Revista Portuguesa de Filosofía, vol. LIX, № 4, 2003, pp. 327-339

42. Según Dörr (p. 432) es interesante observar que los pasos de esta caída, descritos por Heidegger, tienen una extraordinaria similitud con los momentos estructurales que constituyen el fenómeno de la embriaguez y el decurso de los comportamientos de los adictos en general: seducción, aquietamiento, extrañamiento y encierro.

43. Cfr. $§ 40$ de Ser y Tiempo. 
de esa constante tendencia a hacerse uno con las cosas poniéndole ante la inquietante decisión de la propiedad o de la impropiedad de su vida ${ }^{44}$.

Y es que, es consustancial al ser del Dasein en cuanto ser en el mundo, una inclinación al mundo, una propensión a él que puede terminar con el Dasein en el sentido de que puede absorberlo, en el sentido de que puede arrastrarlo hasta provocar el derrumbamiento ontológico de la vida misma. Es una obra de ingeniería conceptual el delimitar bien la distancia entre el entregarse al mundo del que el Dasein se ocupa y la constante tentación de afanarse tanto en las cosas del mundo que, al final, se produce el extrañamiento de la existencia. Por eso la existencia auténtica teniendo que ser en el mundo depende de que ese ser en no implique quedarse en las cosas del mundo, confundirse con ellas, pero tampoco huir del mundo. La deyección en las cosas y la huida de ellas forma parte de un mismo movimiento constitutivo de la inautenticidad de la existencia que busca seguridades y certezas en algo que es pura posibilidad, pura intemperie, pura apertura, pura incertidumbre.

En nuestra opinión, la autenticidad de la existencia humana está a salvo de degenerar en lo neurótico, en la filosofía de Heidegger, cuando se entienda la consecuente vida presente desde lo que, posteriormente y en el contexto de sus reflexiones sobre la técnica, llama serenidad. Obviar la temporalidad en un intento de refugiarse en lo eterno no es tanto remontarse más allá del tiempo cuanto retroceder ante él, no sólo no ampliando nuestras posibilidades sino permaneciendo por debajo de ellas ${ }^{45}$. La serenidad (Gelasenheit) es la disposición emocional y la actitud con la que Heidegger describe la conexión entre el hombre y los entes intramundanos y desde la que, en nuestra opinión, puede comprenderse bien el vivir cuidándose de las cosas y del mundo. Y esto significa vivir sin permitir que las cosas ocupen el lugar de la interioridad, existir hacia afuera sin quedarse fijado en las cosas del presente, sin que quepa entender la serenidad desconectada de la libertad. Distancia para con las cosas, para que estas no nos tengan y sí las tengamos, para que haya espacio entre el Dasein y las cosas que permanentemente le tientan a acompasarse a su ritmo. En mi opinión, la serenidad es la actitud resultante de la influencia que sobre Heidegger ejerció lo que él llamó, la experiencia del cristianismo primitivo en el que las significatividades del mundo real se viven como si no (als ob nich $)^{46}$.

44. Es muy clarificadora la explicación pormenorizada de Juan José García Norro titulada "La disposición afectiva fundamental de la angustia como modo eminente de la aperturidad del Dasein" pp. 169-175 “El cuidado como el ser del Dasein" en R. RODRíGUEz (Coord.), Ser y Tiempo de Heidegger.: Un comentario fenomenológico. Madrid: Tecnos, 2015, pp. 167-195

45. Cfr. Heidegger, M.: El concepto de tiempo. Madrid: Trotta, 2011

46. Cfr. HeIDEgGeR, M.: Introducción a la fenomenología de la religión. Barcelona: Siruela, 2005, p. 146. "El 'como si' expresa un complejo objetual y sugiere la idea de que el cristiano debe desactivar 
El maniaco depresivo no conoce el enfrente libre que resulta de la relación abierta del Dasein con el mundo. El enfermo no puede dejar ni a las cosas ni a los otros hombres en el espacio al que pertenecen pues trastoca la distancia impidiendo la serenidad ante ellos. Este déficit de serenidad o desasimiento resulta patológico precisamente al no permitir que el enfrente sea libre y por tanto no dejar ser ni a las otras cosas, ni a los otros hombres ni a sí mismo.

La serenidad está, pues, en las antípodas de la ansiedad, en cuanto disposición psíquica, aunque la orientación vital otorgadora de sentido sea la misma: el futuro. En el texto Serenidad ${ }^{47}$, Heidegger lo explica así: es necesario servirse de los objetos de forma apropiada pero manteniéndose libre de ellos.

Podemos decir "sí" al inevitable uso de los objetos técnicos y podemos a la vez decir "no" en la medida en que rehusamos a que nos requieran de modo exclusivo, que dobleguen, confundan y, finalmente devasten nuestra esencia ${ }^{48}$.

Este determinado temple de ánimo (Befindlichkeit) evoca, el misterio del ser que envuelve al hombre y que le deja como tarea presente la decisión, la libertad, la opción cotidiana por hacerse auténtico o dejarse embaucar por las cosas. El futuro, pues, queda, desde esta lectura, lejos de lo neurótico siempre que el presente se viva en verdad, esto es, en libertad. De esta manera, la serenidad y la angustia corresponderían a las disposiciones afectivas propias de esa naturaleza jánica del Dasein, a la que nos hemos referido al principio, que nunca puede superar la mundaneidad de ser un ente pero que a la vez reclama una apertura que declara caduca y atribulada toda existencia agotada en el puro yacer del ahora presente.

\section{Bibliografía}

BLANKEnbuRG, W.:"Daseinsanalyse”. In: J. RITTER (ed.): Historisches Wörterbuch der Philosophie II. Darmstadt, 1972.

CAPURRO, R.: "Análisis existencia y relación terapéutica: la influencia de Martin Heidegger en la obra de L. Binswanger y M. Boss" en Revista Portuguesa de Filosofía, vol. LIX, no 4, 2003, pp. 327-339

esas referencias al mundo circundante" p. 149.

47. Heidegger, M.: Serenidad. Barcelona: Serbal, 1994. Conferencia pronunciada en 1955 con ocasión del 175 aniversario de compositor Konrradin Kreutzer

48. HEIDEGGER, M.: Serenidad, pp. 26-27 
DÖRR, O.: Psiquiatría antropológica. Contribuciones a una psiquiatría de orientación fenomenológico-antropológica. Santiago: Universitarias, 1995

GARCíA NORRO, J. J. "El cuidado como el ser del Dasein" en R. ROdríguez (Coord.). Ser y Tiempo de Heidegger, M.: Un comentario fenomenológico. Madrid: Tecnos, 2015, pp. 167-195

GANDER, H. H.: "La fenomenología hermenéutica del vivir fáctico de Heidegger" en F. DUQUE (ed.), Sendas que vienen, Madrid, Universidad Autónoma de Madrid, 2008, pp. 139-171

HeIDEgGeR, M.: Ontologie. Hermeneutik der Faktizität. GA 63. Vittorio Klostermann: Frankfurt a. M., 1988

HEIDEGGER, M.: Logik. Die Frage nach der Warheit. GA 21, Vittorio Klostermann: Frankfurt a. M., 1976

HeIDEgGeR, M.: Hölderlins Hymnen "Germanien" und "Der Rhein". GA 39, Vittorio Klostermann: Frankfurt a. M., 1980

HEIDEGGER, M.: Ser y Tiempo. México: FCE, 1967

HEIDEGGER, M.: Seminarios de Zollikon. Barcelona: Herder, 2006

HEIDEGGER, M.: Schwarze Hefte: Überlegungen II-VI (1931-1938). Frankfurt a. M: Vittorio Klostermann, 2014.

HEIDEGGER, M.: El concepto de tiempo. Madrid: Trotta, 2011

HEIDEGGER, M.: Introducción a la fenomenología de la religión. Barcelona: Siruela, 2005 HEIDEGGER, M.: Serenidad. Barcelona: Serbal, 1994.

PATOcKA, J.: Introducción a la fenomenología. Barcelona: Herder, 2008.

WALTON, R.: "Temporeidad e historicidad" en RODRíGUEz, R.: Ser y Tiempo de Heidegger. Un comentario fenomenológico. Madrid: Tecnos, 2015, pp. 371-397

XOLOCOTZI YÁÑEZ, A.: "Los encuentros de Heidegger con la psiquiatría: Badenweiler y Zollikon", en La lámpara de Diógenes, no 16 y 17, pp. 7-23 